\title{
O ESTADO COMO CONSUMIDOR: E A SUA VULNERABILIDADE TÉCNICA
}

Cleyton Heleno Pereira da silva,

Universidade do Oeste Paulista - UNOESTE, Curso de Direito, Presidente Prudente, SP. E-mail:-cle_2411@hotmail.com

\section{RESUMO}

A presente pesquisa, tem por finalidade refletir sobre a inaplicabilidade do Código de defesa do consumidor, nas relações consumeristas onde figure o Estado como consumidor, em virtude de sua condição de supremacia frente ao Fornecedor, dado pela Lei de licitações, o mesmo não enquadra-se no conceito do artigo 20 do referido diploma legal. Assim para que a pesquisa transcorra adequadamente, adotou-se o método hipotético-dedutivo, realizado através de revisão bibliográfica, com a utilização de doutrina, jurisprudência, artigos eletrônicos, normas constitucionais e infraconstitucionais. Conclui-se que deve ser aplicado o Código de defesa do consumidor nas relações de consumo do Estado, quando demostrada a condição de vulnerabilidade do Estado, frente a expertise do fornecedor.

Palavras chaves: Relação de consumo, Vulnerabilidade, Estado consumidor, Código de defesa do consumidor.

\section{THE STATE AS A CONSUMER: AND ITS TECHNICAL VULNERABILITY}

\section{ABSTRACT}

The purpose of this research is to reflect on the inapplicability of the Consumer Protection Code, in the consumer relations where the State appears as a consumer, due to its condition of supremacy vis-a-vis the Supplier, given by the Law of competitive bidding, is based on the concept of article 2 of the above-mentioned law. Thus, in order for the research to proceed properly, the hypothetical-deductive method was adopted through a bibliographical review, using doctrine, jurisprudence, electronic articles, constitutional and infraconstitutional norms. It is concluded that the Consumer Protection Code should be applied in the State's consumer relations, when the State's vulnerability condition is demonstrated, in the face of the supplier's expertise.

Keywords: Consumer relationship, Vulnerability, Consumer state, Consumer protection code. 


\section{INTRODUÇÃO}

Ao longo dos anos verifica-se que existe uma grande divergência doutrinaria assim como jurisprudencial em atribuir ou não ao Estado à condição análoga de consumidor, enquadrando-o assim no conceito previsto no artigo 20 do Código de defesa do consumidor quando contratar prestações de serviços e obras em prol a sociedade.

Para que a pesquisa se desenvolva de modo adequado e necessário a realização de um questionamento e posteriormente responde-lo: existe a possibilidade de o código de defesa do consumidor incidir sobre a relação contratual realizada pelo Estado, (Administração pública) com fornecedores ou prestadores de serviço?

O presente trabalho será desenvolvido a partir do estudo reflexivo dos princípios constitucionais analisando as teorias que definem o conceito de consumidor com ênfase nas espécies de vulnerabilidades para posteriormente nos posicionarmos diante do estudado, reflexionando sobre as divergências doutrinarias construída ao longo dos anos, entretanto esta pesquisa não esgota a possibilidade de futuros estudos. Será aplicado o método hipotético dedutivo, apoiando-se na edificação doutrinária, jurisprudencial e normativa, assim como pesquisa bibliográfica por meio uma ampla leitura de artigos científicos, doutrina e jurisprudência.

\section{DO DIREITO DO CONSUMIDOR}

O Direito do Consumidor surgiu da evidente necessidade de adequação do direito às novas realidades trazidas pelo desenvolvimento industrial pós Revolução Industrial, a fim de adaptar, melhorar e recompor a igualdade entre as partes, na relação de consumo, no qual encontrava-se totalmente estilhaçada e fragilizada, devido as rápidas transformações socioeconômicas, buscando reestabelecer o equilíbrio e a justiça na relação contratual.

A relação de consumo faz parte da vida cotidiana assim como da história do ser humano, impossível seria dizer que os indivíduos não consumiram ou deixaram de consumir. No entanto ao longo dos séculos as relações de consumo têm passado por diversas transformações, partindo de períodos mais extremos até os dias atuais.

Após a Revolução Industrial, com o aumento exacerbado da industrialização dos produtos, e inobservância na qualidade dos mesmos, os consumidores passaram a adquirir produtos tendenciosamente defeituosos e viciados.

Devido esses fatores extremamente relevantes, nossa magna carta promulgada em 1988, previu a elaboração de uma Lei especifica de proteção ao consumidor, previsto no artigo 48 das disposições transitórias.

Art. 48. O Congresso Nacional, dentro de cento e vinte dias da promulgação da Constituição, elaborará código de defesa do consumidor. (BRASIL, 1988).

Sendo instituída a Lei 8.078 de 1990, o Código de Defesa Do Consumidor, que foi elaborado buscando proteger o elo mais fragilizado nas relações de consumo, ou seja, o consumidor.

O Código de defesa do consumidor, foi elaborado buscando equilibrar as relações de consumo, visto que os objetivos principais do código era suprir as necessidades do consumidor, garantindo-Ihe os direitos fundamentais previsto em nossa magna carta.

Verifica-se que o código criado nada mais é do que um retrato de uma sociedade consumerista que necessitava de uma norma para assegurar-lhes nas relações de consumo, preconizando o previsto no artigo 4을 do Código de Defesa do Consumidor:

Art. 4- A Política Nacional das Relações de Consumo tem por objetivo o atendimento das necessidades dos consumidores, o respeito à sua dignidade, saúde e segurança, a proteção de seus interesses econômicos, a melhoria da sua qualidade de vida, bem como a transparência e harmonia das relações de consumo, atendidos os seguintes princípios: (BRASIL, 1990). 
Segundo o Autor João Calvão da Silva, os consumidores são assegurados com relação: "a proteção contra práticas abusivas comerciais desleais e abusivas; informação, formação e educação do consumidor, representação, organização e consulta; proteção do consumidor contra produtos defeituosos e perigosos". (SOARES apud SILVA, 2013).

O Código de defesa do consumidor assegura o consumidor contra todas as hipóteses apresentada pelo autor, no entanto precisamos conceituar a figura do fornecedor e do consumidor.

Nas relações de consumo, verifica-se a existência de duas figuras distintas ocupando polos opostos, de um lado vemos a figura do fornecedor, possuidor direto do objeto ou prestador de serviço, do outro lado tem a figura do consumidor, este pessoa física ou jurídica, no qual possui interesse em adquirir determinado bem ou serviço.

O conceito doutrinário de consumidor é extremamente abrangente, sendo possível considerar consumidor, qualquer indivíduo que adquira ou utilize produto ou serviço na condição de destinatário final, alcançando até mesmo os possíveis adquirentes ou usuários de produtos e serviços. (MAZZILLI, 2016, p. 211)

Realizando uma simples leitura do Código de Defesa do Consumidor, no artigo 2 o nota-se que consumidor seria as pessoas físicas (natural) e também as pessoas jurídicas, aplicando esta última de qualquer natureza. De acordo com Nehemias Domingos Melo (2010, p. 13):

Não se há de ficar adstrito à figura do consumidor stricto sensu previsto no caput do art. $2^{\circ}$, que prevê como tal aquele que seja destinatário final se um produto ou serviço, pois é forçoso que se amplie esta conceituação porque o legislador, no parágrafo único do mesmo artigo, criou a figura do consumidor por equiparação ao prever a coletividade de pessoas, ainda que indetermináveis, desde que tenham intervindo nas relações de consumo, devem ser equiparadas a consumidores.

O legislador conceitua consumidor, no artigo 2ํe seu parágrafo único do Código de Defesa do Consumidor (CDC), trazendo um conceito legal abrangente:

Art. $2^{\circ}$ Consumidor é toda pessoa física ou jurídica que adquire ou utiliza produto ou serviço como destinatário final.

Parágrafo único. Equipara-se a consumidor a coletividade de pessoas, ainda que indetermináveis, que haja intervindo nas relações de consumo.(BRASIL, 1990)

Nota-se que, o CDC diante de sua extensa abrangência contempla o status de consumidor, a todos os indivíduos atingidos independentemente de ter intervindo na relação contratual entre consumidor e fornecedor.

Como vimos o Consumidor e apenas uma das partes que compõe o elo da relação consumerista na outra ponta da relação encontra-se o fornecedor. $\mathrm{O}$ artigo 3 ㅇ do CDC nos traz 0 conceito legal de fornecedor:

Art. $3^{\circ}$ Fornecedor é toda pessoa física ou jurídica, pública ou privada, nacional ou estrangeira, bem como os entes despersonalizados, que desenvolvem atividade de produção, montagem, criação, construção, transformação, importação, exportação, distribuição ou comercialização de produtos ou prestação de serviços. (BRASIL, 1990).

Realizando um breve analise do conceito legal é possível sintetizar que o fornecedor, pode ser tanto pessoa jurídica como pessoa física. A pessoa física geralmente e pouco notada como fornecedora de algum produto ou serviço, visto que geralmente essa função e exercida por uma pessoa jurídica.

Ressalta-se que, a qualidade de fornecedor trazida pelo CDC estende-se também aos entes despersonalizados, ou seja, a qualidade de fornecedor permanece mesmo após a personalidade jurídica ser extinta segundo Rizzatto Nunes (2005, p. 88 e 89):

A colocação do termo "ente despersonalizado" leva-nos a pensar primeiramente na massa falida, o que é adequado. Importante notar que, apesar de uma pessoa jurídica falir, 
existirão no mercado produtos e, eventualmente, resultados dos serviços que ela ofereceu e efetivou, e que continuarão sob a proteção da lei consumerista.

O autor nos traz a ideia de que independente do fornecedor ter falido, a massa falida permanece responsável, pois ainda permanecerão no mercado de consumo, os produtos e assim prolongando no tempo os efeitos dos serviços e produtos ofertados, não extinguindo assim os direitos e garantias do consumidor.

\section{DA VULNERABILIDADE E HIPOSSUFICIENCIA DO CONSUMIDOR}

Conforme verificou-se anteriormente, o Código de Defesa do Consumidor foi instituído para resguardar direitos violados pela expertise do fornecedor, buscando-se assim manter o equilíbrio nas relações consumerista entre fornecedor e consumidor. Diante do intuito de assegurar o equilíbrio, acerca das relações de consumo, nota-se que a doutrina não e unanime em relação a figura do consumidor, ora ressalta-se a existência de três teorias adotadas, a finalista pura, maximalista e a maximalista mitigada ou finalista aprofundada.

Com relação a teoria finalista Tartuce $(2017$, p. 88) afirma que tal modelo foi adotado expressamente pelo art. 2ำ do Código Brasileiro de Defesa do Consumidor para a qualificação do consumidor, sendo necessário o elemento destinario final seja do produto ou do serviço prestado pelo fornecedor.

Claudia Lima Marques, leciona sobre o que compreende ser destinatário final:

Destinatário final seria aquele destinatário fático e econômico do bem ou serviço, seja ele pessoa jurídica ou física. Logo, segundo essa interpretação teleológica, não basta ser destinatário fático do produto, retirá-lo da cadeia de produção, levá-lo para o escritório ou residência - é necessário ser destinatário econômico do bem, não adquiri-lo para revenda, não adquiri-lo para uso profissional, pois o bem seria novamente um instrumento de produção, cujo preço será incluído no preço final do profissional para adquiri-lo. Nesse caso, não haveria exigida 'destinação final' do produto ou do serviço, ou, como afirma o STJ, haveria consumo intermediário, ainda dentro das cadeias de produção e de distribuição. Essa interpretação restringe a figura do consumidor àquele que adquire (utiliza) um produto para uso próprio e de sua família, consumidor seria o não profissional, pois o fim do CDC é tutelar de maneira especial um grupo da sociedade que é mais vulnerável.(MARQUES apud TARTUCE, 2017, p.88).

Destarte, nota-se que essa teoria compreende como consumidor exclusivamente aquele indivíduo que busque retirar o bem ou serviço do mercado para uso final interrompendo assim a cadeia produtiva, sendo este considerado destinatário final.

A teoria maximalista conforme elucida Tartuce(2017, p.89), busca ampliar o conceito atribuído ao consumidor. Afirma o doutrinador que os maximalistas entendem que a definição do art. 20 deve ser interpretada o mais extensivamente possível, segundo esta corrente, para que as normas do CDC possam ser aplicadas a um número cada vez maior de relações de consumo.

Deste modo, com relação a teoria maximalista, torna-se possível afirmar que ela amplia o conceito atribuído a consumidor, possibilitando que qualquer indivíduo seja considerado consumidor final independente deste pôr fim a cadeia produtiva ou não, os adeptos a essa teoria realizam uma interpretação totalmente extensiva ao artigo 2o do diploma legal estudado.

Já a teoria finalista aprofundada, trata-se de uma teoria intermediária, criada pelo Superior Tribunal de Justiça, no qual analisa no caso em concreto o porte econômico do consumidor verificando assim a existência de vulnerabilidade na relação consumerista.

Cláudia Lima Marques expõe em sua obra acerca da corrente finalista aprofundada:

[...]depois da entrada em vigor do $\mathrm{CC} / 2002$ a visão maximalista diminuiu em força, tendo sido muito importante para isto a atuação do STJ. Desde a entrada em vigor do CC/2002, parece-me crescer uma tendência nova da jurisprudência, concentrada na noção de 
consumidor final imediato (Endverbraucher), e de vulnerabilidade (art. 4으, I), que poderíamos denominar aqui de finalismo aprofundado.(MARQUES, 2010 apud TARTUCE, 2017, p.93).

Neste diapasão, o Superior Tribunal de Justiça vem entendendo, ser adequado a aplicação da teoria finalista aprofundada, apreciando no caso em concreto a existência dos pressupostos para a caracterização da relação de consumo, ou seja a hipossuficiência e a vulnerabilidade.

STJ. TERCEIRA TURMA. AGRAVO REGIMENTAL NO RECURSO ESPECIALNNo 1149195. REL. MIN. SIDNEI BENETI. DJE DATA: 01/08/2013 EMENTA: DIREITO CIVIL E PROCESSUAL CIVIL. CÓDIGO DE DEFESA DO CONSUMIDOR PARA PROTEÇÃO DE PESSOA JURÍDICA. TEORIA FINALISTA APROFUNDADA. REQUISITO DA VULNERABILIDADE NÃO CARACTERIZADO. EXIGIBILIDADE DE OBRIGAÇÃO ASSUMIDA EM MOEDA ESTRANGEIRA. FUNDAMENTO DO ACÓRDÃO NÃO ATACADO. 1.- A jurisprudência desta Corte tem mitigado os rigores da teoria finalista para autorizar a incidência do Código de Defesa do Consumidor nas hipóteses em que a parte (pessoa física ou jurídica), embora não seja tecnicamente a destinatária final do produto ou serviço, se apresenta em situação de vulnerabilidade.[...].(BRASIL, 2013, p.1 GRIFO NOSSO).

Deste modo, a teoria finalista diferentemente das outras duas já esplanadas, mostra-se mais adequando ao conceituar consumidor, levando em consideração a condição do indivíduo perante seu fornecedor analisando assim no caso em concreto as condições de vulnerabilidade e hipossuficiência do consumidor. Assim nota-se que a vulnerabilidade é um dos pilares de sustentação desta teoria, assim como da lei $8.078 / 1990$, está previsto no capítulo voltado à Política Nacional de Relações de Consumo, no seu art. 4으, inciso I.

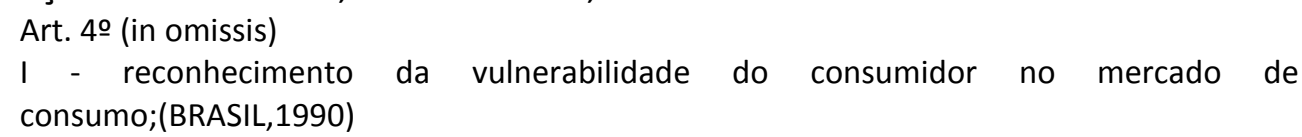

A doutrina classifica a vulnerabilidade em tres especies: a fática, a jurídica e a técnica: A vulnerabilidade fática é a real desproporção fática de forças existentes entre as figuras da relação consumerista. $O$ consumidor é abalisado fraco ante o fornecedor.

Já a denominada vulnerabilidade jurídica, refere-se impossibilidade de possuira conhecimentos jurídicos, econômicos e contábeis específicos, para que suceda uma celebração contratual equilibrada.

Por ultimo, não menos importante, a vulnerabilidade técnica ocorre quando o consumidor não possui conhecimentos técnicos específicos sobre o produto ou serviço, encontrando-se em situação profícua a engano.

\section{O ESTADO E AS RELAÇÕES DE CONSUMO}

O Estado em virtude do bem estar social, por intermédio da administração pública contrata obras e serviços, que devem alcançar o gozo satisfatório da sociedade em geral.

Sendo assim, o Estado devido suas necessidade é obrigado a pactuar com determinadas empresas em prol da sociedade, vindo estes contratos a serem regidos pela Lei $n=8.666 / 93$ Lei de Licitações e Contratos.(BRASIL, 1993).

A doutrina entende que, a lei especial oferece inúmeras benesses ao Estado quando contrata com fornecedores, concedendo-lhe um status de supremacia, não devendo assim sem amparado pela égide do Código de Defesa do Consumidor.

Fundamentou-se, essa teoria através do disposto no artigo 76 da Lei 8.666/93 que traz a seguinte redação:

Art. 76. A Administração rejeitará, no todo ou em parte, obra, serviço ou fornecimento executado em desacordo com o contrato.(BRASIL, 1993). 
Entretanto, embora o Estado possua essa faculdade de poder dispor as exigências da prestação de serviço e podendo ele mesmo recusar a prestação divergente do que pactuado.

Ressalta-se, que o artigo 54 do mesmo diploma legal que alinhava as disposições acerca dos contratos administrativos, afirmando que os contratos administrativos "se regem pelas suas cláusulas assim como pelos preceitos de direito público e de direito privado mesmo que subsidiariamente".(BRASIL,1993).

O Código de Defesa do Consumidor, ao tartar das figuras da relação de consumo, busca tratar desigualmente pessoas desiguais para que haja igualdade entre os desiguais, "levando-se em conta que o consumidor está em situação de manifesta inferioridade frente ao fornecedor de bens e serviços".(FILOMENO,1995, p. 26).

Como ja mencionado anteriormente, grande parte da doutrina não considera o Estado como consumidor, pois para assim ser considerado deve existir uma das vulnerabilidade o que muito não conseguem visualizar em virtude do status de supremacia concedido pela Lei 8666/93, ou seja, não reconhecem o desequilibrio entre o Estado e o forncedor.

Entretanto, o Estado em alguns casos mostra-se vulneravel técnicamente, ou seja, é possivel observar que ao pactuar com um fornecedor uma obra ou serviços, por meio de licitação ou não, o Estado o faz por intermedio de uma pessoa, que comumente não possui conhecimento técnico ou cientifico para realizar uma analise do objeto oferecido pelo fornecedor, esse expertise no objeto ofertado, realizando o contrato muitas vezes por fatores econimicos conforme assevera a Lei de Licitações.

\section{CONSIDERAÇÕES FINAIS}

Ante todo o exposto, conclui-se que os contratos consumerista atualmente tem como principal característica a proteção do elo mais vulnerável. Destaca-se que ante a teoria adotada pelos mais ilustres doutrinadores, assim como pelos tribunais superiores a vulnerabilidade deve ser estendida a todos que dela participem. Entretanto, deve-se analisar o caso concreto a real existência de alguma das modalidade de vulnerabilidade.

Verificou-se, que a conceituação aludida não exclui, de maneira automática, as pessoas jurídicas, tampouco o Estado, visto possuir natureza jurídica de direito público.

Nota-se que, os contratos administrativos, regidos pela égide da Lei no 8666/93, não fornece uma proteção completa à Administração Pública, que, nos termos do art. 54 da Lei pode se utilizar supletivamente das normas de direito privado, assim como o Código de Defesa do Consumidor.

Deste modo, Mostra-se possível e viável que ao analisar o caso em concreto onde figure o ente público como consumidor e fique constatada sua vulnerabilidade técnica, frente a expertise do fornecedor, perfazendo assim jus a égide do Código de Defesa do Consumidor.

\section{REFERÊNCIAS}

BRASIL, República Federativa do. Código de defesa do consumidor. Promulgada em 11 de setembro de 1990. Disponível em <http://www.planalto.gov.br/ccivil_03/leis/l8078.htm>.acesso em 21 Mar. 2018.

BRASIL, República Federativa do. Constituição Federal. Promulgada em 05 de outubro de 1988. Disponível

em:<http://www.planalto.gov.br/ccivil_03/constituicao/constituicaocompilado.htm>.Acesso em 09 Jul. 2018. 
BRASIL. Superior Tribunal de Justiça. 3a Turma. Agravo Regimental no Recurso Especial no 1149195. Relator: Sidnei Beneti. Brasília, 01 de agosto de 2013. Disponível em: <http://www.jf.jus.br/juris/unificada/Resposta>. Acesso em: 23 abr. 2018.

Filomeno, José Brito. In: Código brasileiro de defesa do consumidor comentado pelos autores do anteprojeto. 4. ed. Rio de Janeiro: Forense Universitária, 1995, p. 26.

MAZZILLI, Hugo Nigro. A defesa dos interesses difusos em juízo. 29. ed. São Paulo: Saraiva, 2016.

MELO, Nehemias Domingos de. Da defesa do consumidor em juízo. São Paulo: Atlas. 2010, p. 13.

NUNES, Luiz Antônio Rizzatto. Ações coletivas e as definições d direito difuso, coletivo e individual homogêneo. São Paulo: Quartier Latin, 2005, p. 101-103.

SILVA, Jorge Alberto Quadros de Carvalho. Código de defesa do consumidor anotado e legislação complementar. 6. ed. São Paulo: Saraiva, 2008.

SILINGOVSCHI, R.R.L.et al. Normas e padrões para trabalhos acadêmicos e científicos da Unoeste. Presidente Prudente: Unoeste.2015.

TARTUCE, Flavio, NEVES, Daniel Amorim Assumpção. Manual de direito do consumidor. Direito Material e Processual. 6 ed. São Paulo: Método. 2017, p. 80-95 